\title{
ÚLCERA DE MOOREN BILATERAL
}

\author{
Juan Fernando DiazGranados Mesa MD*, Miriam Ibeth Isaza Gómez MD**, Lupe van Heyl Cleves MD***
}

\section{Resumen}

Objetivo: describir el caso de un paciente con úlcera de Mooren bilateral en el Hospital de San José. Metodología: revisión y análisis de historia clínica. Resultados: paciente de 21 años sin antecedentes sistémicos, de ocupación carnicero, que consultó por ojo rojo, fotofobia y lagrimeo en ojo izquierdo y ardor en el derecho de dos días de evolución. Refería haber presentado seis episodios similares en los últimos seis meses. Al examen se encontró una úlcera corneana periférica en OD entre meridianos 9:00 y 11:00 y en el OI entre 1:00 y 6:00, de forma alargada, con borde anterior serpiginoso, levantado, infiltrado y socavado, y con compromiso parcial del epitelio. Se diagnosticó úlcera de Mooren bilateral, se inició tratamiento tópico con prednisona, ciclosporina, diclofenaco, lubricantes, inhibidor de la colagenasa y lente de contacto terapéutico. Se solicitaron exámenes paraclínicos y valoración por medicina interna, descartando enfermedad sistémica asociada. Después se solicitaron linfocitos totales, linfocitos CD2, CD4 y CD8, C3, C4, IgA total sérica, anticuerpos anticisticerco y coproscópico seriado. Conclusiones: por la rareza de esta entidad en nuestro medio y por interés académico presentamos este caso, cuyo diagnóstico fue clínico, haciendo énfasis en las características biomicroscoscópicas de esta patología.

Palabras clave: úlcera corneana periférica, crónica, autoinmune, diagnóstico clínico.

Abreviaturas: OD, ojo derecho; OI, ojo izquierdo.

\section{BILATERAL MOOREN'S ULCER}

\section{Abstract}

Objective: to describe the case of one man with bilateral Mooren's ulcer diagnosed at Hospital de San José. Methodology: review and analysis of clinical record. Results: the patient is a 21-year old man with no systemic antecedents, he is a butcher and presented with a 2-day history of: red eye, photophobia and increased tears on left eye and burn sensation in right eye. He refers six similar episodes in the last six months. Medical examination revealed peripheral corneal ulcers located between meridians 9:00 and 11:00 in the right eye and between 1:00 and 6:00 in the left eye; ulcers were: elongated, sinuous, elevated, infiltrative, excavated and partially compromised the overlying epithelium. Diagnosis was: bilateral Mooren's ulcers. Treatment with topical prednisone, cyclosporine, diclofenac, lubricants, collagenase inhibitors and therapeutic contact lenses was initiated. Lab work-up and internal medicine consultation ruled out associated systemic disease. Further lab work-up including total lymphocyte, CD2, CD4 and CD8 lymphocyte count, determination of C3, C4, total serum IgA, and cysticercoids antibodies and serial stool examination was requested. Conclusions: we report this case for this condition rarely occurs in our setting and for being of academic interest. The diagnosis was clinical, and biological/ microscopic features of this condition are highlighted.

Key words: peripheral corneal ulcer, chronic, autoimmune, clinical diagnosis.

Fecha recibido: abril 22 de 2009 - Fecha aceptado: febrero I de 2010

* Oftalmólogo subespecialista en córnea y cirugía del segmento anterior. Jefe del Servicio de Oftalmología del Hospital de San José. Profesor Asociado, Fundación Universitaria de Ciencias de la Salud, Bogotá. DC. Colombia.
** Residente III Oftalmología, Fundación Universitaria de Ciencias de la Salud, Hospital de San José. Bogotá, DC. Colombia.

*** Residente II Oftalmología. Fundación Universitaria de Ciencias de la Salud, Hospital de San José. Bogotá DC. Colombia. 


\section{Justificación}

La úlcera de Mooren es una entidad con una incidencia aproximada de uno en $2.200^{1}$, localizada en la córnea periférica. Debido a su baja incidencia y por interés académico reportamos este caso, en el cual el diagnóstico se realizó por las características biomicroscópicas. Es importante descartar otras patologías, en especial la queratitis ulcerativa periférica, la cual tiene hallazgos clínicos similares pero implicaciones sistémicas importantes que pueden incluso comprometer la vida del paciente.

\section{Reporte de caso}

Paciente de sexo masculino de 21 años de edad procedente de Bogotá, de ocupación carnicero, que ingresa al servicio de urgencias del Hospital de San José. Refiere cuadro clínico de dos días de evolución consistente en fotofobia, lagrimeo, ojo rojo izquierdo y leve ardor en OD. Niega otros síntomas. Informa haber presentado seis episodios similares en los últimos seis meses, el último un mes antes manejado en otra institución con prednisona tópica al $1 \%$ cada ocho horas durante tres semanas, presentando mejoría de los síntomas. Los antecedentes y la revisión por sistemas son negativos.

Al examen presentaba una agudeza visual de 20/25 en OD y 20/30 en OI. Bajo la lámpara de hendidura se observó una úlcera corneana periférica en OD entre meridianos 9:00 y 11:00, y en OI entre 1:00 y 6:00, de forma alargada o de surco, con borde anterior serpiginoso, levantado, infiltrado y socavado. El resto del examen oftalmológico se encontró dentro de límites normales.

Con este cuadro se realiza el diagnóstico clínico de úlcera de Mooren bilateral y se inicia manejo con aplicación tópica de prednisona al $1 \%$ cada seis horas, ciclosporina al $0,1 \%$ cada doce horas, $\mathrm{N}$-acetilcisteína cada seis horas, lubricación en colirio cada 30 minutos y en gel cada dos horas en ambos ojos, y en OI lente de contacto terapéutico, además de diclofenaco cada ocho horas. Las cifras de factor reumatoideo, velocidad de sedimentación globular y serología fueron normales. La valoración por medicina interna descartó compromiso sistémico. Se solicitan linfocitos totales, CD2, CD4 y CD8, C3 y C4, IgA sérica total, anticuerpos anticisticerco y coproscópico seriado con el fin de descartar parasitosis. Lamentablemente el paciente no regresó y no pudimos obtener información de dichos exámenes paraclínicos, pero en virtud a que éste es un diagnóstico clínico insistimos en presentar el caso.

\section{Discusión}

Por la rareza de esta entidad en nuestro medio y el interés académico, reportamos este caso cuyo diagnóstico fue clínico, haciendo énfasis en las características biomicroscópicas de esta patología. Como bien lo describe la literatura, es una enfermedad de la córnea periférica con signos clínicos específicos que permiten diagnosticarla mediante el examen clínico. Es importante la realización de exámenes paraclínicos con el fin de descartar los diagnósticos diferenciales, ya que no existe una prueba que sea característica de esta afección. No se debe olvidar que es mandatorio descartar la queratitis ulcerativa periférica, muy similar en su presentación clínica, pero con serias implicaciones sistémicas que requieren manejo oportuno, no sólo para disminuir la morbilidad ocular, sino también la morbimortalidad ya que es una manifestación de una enfermedad sistémica potencialmente fatal.

\section{Revisión de la literatura}

La úlcera de Mooren es una entidad rara con incidencia aproximada de uno en $2.200,{ }^{1}$ de probable origen inmunológico, caracterizada por una úlcera crónica y dolorosa de la córnea periférica. Fue descrita primero por Bowman en 1849 y publicada por MacKenzie en 1854; aunque fue Mooren en 1867 el primero en describir de manera clara la patología y considerarla como una entidad clínica. En 1902 Nettleship realizó la primera revisión de la literatura encontrando 78 casos. ${ }^{2}$ A partir de este momento han sido varias las revisiones e investigaciones que se han realizado sobre esta entidad, pero sigue siendo incierta la fisiopatología y el entendimiento de esta devastadora condición.

Aunque la patogénesis se desconoce, la evidencia científica sugiere un desorden autoinmune localizado, en el que se producen autoanticuerpos contra la córnea y la 


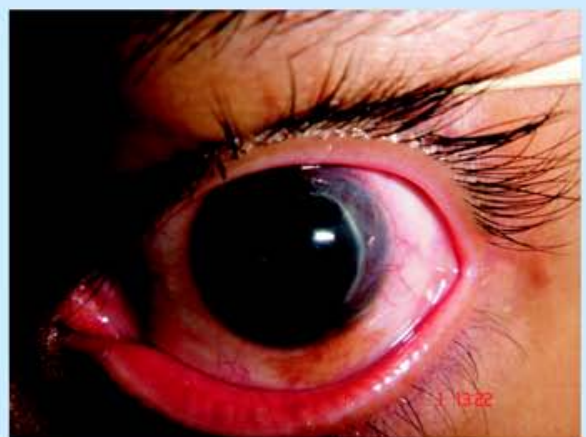

OI: úlcera corneana periférica entre meridianos 1:00 a 6:00.

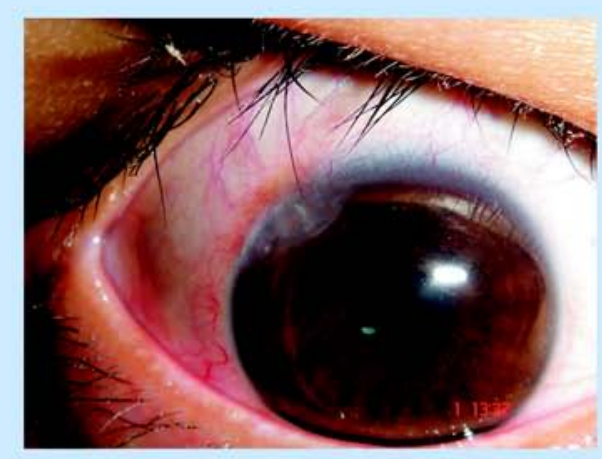

OD: úlcera corneana periférica entre meridianos 9:30 a 10:30.

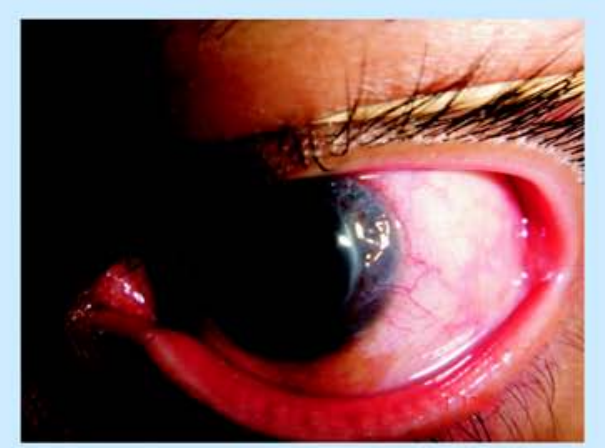

Úlcera de forma alargada.

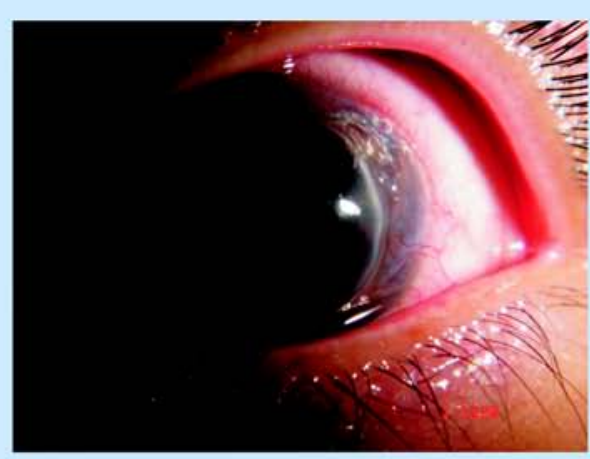

Úlcera con borde anterior serpiginoso.

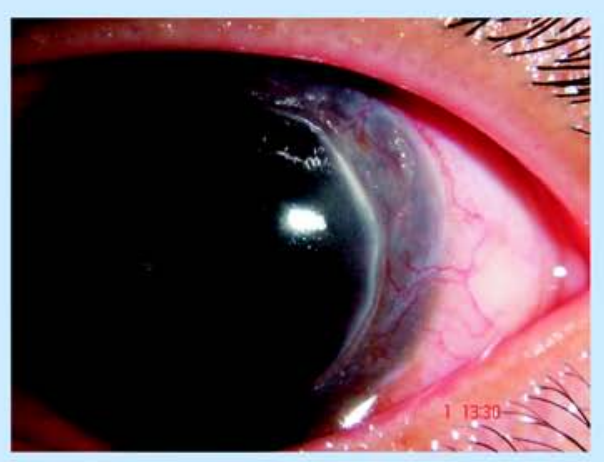

Úlcera con borde socavado.

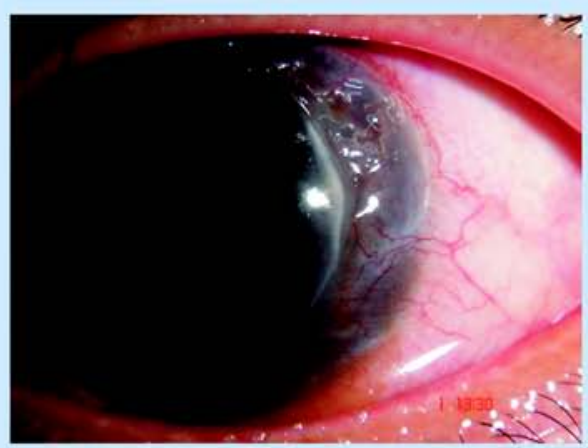

Úlcera con borde anterior levantado e infiltrado.

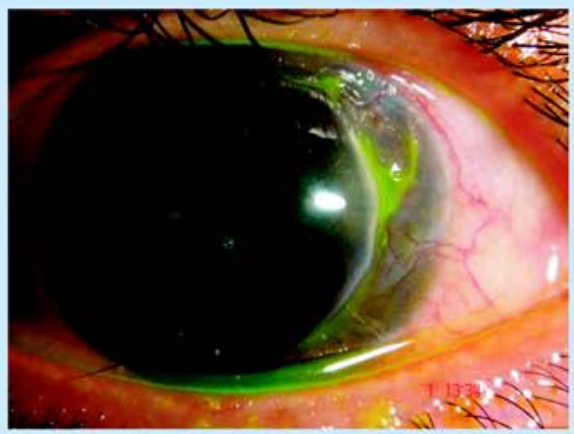

Úlcera con compromiso parcial del epitelio. 
conjuntiva. ${ }^{2}$ También es posible que la inflamación que se asocia con trauma o infección altere los antígenos superficiales de la córnea y conjuntiva, predisponiendo al desarrollo de autoanticuerpos. Se ha identificado en esta entidad la presencia de células plasmáticas, leucocitos, eosinófilos, mastocitos, inmunoglobulinas, complemento y alteración de la relación linfocitos T supresores/citotóxicos. ${ }^{1}$ Lo anterior ha llevado a deducir la participación tanto del sistema inmune celular como del humoral en el proceso fisiopatológico. Se ha comprendido mejor al conocer las características inmunes de la córnea. Como bien es sabido, la parte central difiere en muchos aspectos de la periférica, presentando ésta última niveles mucho más altos de células de Langerhans, IgM y complemento, como resultado de la proximidad con los vasos limbares. ${ }^{3,4}$ Por lo anterior, la córnea periférica es el sitio que primero se ve comprometido en esta patología. A medida que los vasos sanguíneos se dirigen hacia el centro de la córnea, el proceso inflamatorio afecta también esta zona.

Se ha postulado que la úlcera de Mooren encontrada en pacientes africanos podría ser desencadenada por infecciones parasitarias, ${ }^{2}$ apoyado por estudios como el de Majekodunmi, quien encontró helmintiasis en cuatro de cinco pacientes. Por otro lado Trojan encontró que 14 de 34 enfermos con diagnóstico de úlcera de Mooren y helmintiasis, después de haber sido manejados con terapia antihelmíntica, presentaron mejoría del proceso ulcerativo. ${ }^{1}$ La alta incidencia de ulceración con helmintiasis sugiere que estos organismos presentan alguna relación con la etiología de esta condición. Parece que la úlcera es ocasionada por una reacción antígeno-anticuerpo a la toxina helmíntica o a otros antígenos que se depositan en la córnea periférica durante la fase sanguínea de la infección. También es posible que la infección parasitaria altere de alguna manera el sistema inmune causando la formación de la úlcera corneana.

Kaufman y Wood describieron dos tipos clínicos de la entidad. ${ }^{1}$ El primero llamado limitado se presenta de manera característica en pacientes mayores, unilateral, con síntomatología leve y progresión lenta, respondiendo bien a la terapia médica o quirúrgica. El segundo tipo, más agresivo, se presenta bilateral en pacientes más jóvenes y se caracteriza por ser muy doloroso, con curso clínico rápidamente progresivo y presentar poca respuesta a cualquier tipo de tratamiento.

La úlcera de Mooren se caracteriza por dolor severo asociado con fotofobia, lagrimeo excesivo y disminución de la agudeza visual. Se presenta como una ulceración crónica y dolorosa de la córnea periférica. Comienza como un infiltrado en el estroma anterior periférico, que progresa a una úlcera en forma de surco, con bordes serpiginosos y socavados, sin intervalo claro entre ésta y el limbo. En algunas áreas de la lesión puede encontrarse epitelio sano, ya que la inflamación y destrucción comprometen en esencia el estroma. Progresa en forma circunferencial hasta comprometerla en su totalidad, dejando a su paso una córnea opaca, adelgazada y vascularizada. Cuando se compromete el limbo se presenta inflamación de la conjuntiva y en casos más severos, la epiesclera e incluso la esclera.

La disminución de la agudeza visual puede producirse como resultado del compromiso del eje visual o del astigmatismo irregular producido por el adelgazamiento periférico de la córnea. El resultado final es una córnea cicatrizada con compromiso importante de la agudeza visual. La perforación ocular ocurre en el $36 \%$ de los pacientes afectados, sobre todo si se presenta trauma. ${ }^{1}$

El diagnóstico es en esencia clínico, basado en las características de la entidad. Es importante descartar otras causas de queratitis ulcerativa periférica asociadas con patologías sistémicas como afecciones colágenovasculares, infecciones tipo sífilis o gonorrea, leucemia, degeneraciones como la marginal de Terrien y la pelúcida, y procesos infecciosos por Staphylococcus, Gonococcus y Moraxella. El estudio de laboratorio de cualquier paciente con queratitis ulcerativa periférica comprende el recuento de células sanguíneas, velocidad de sedimentación globular, factor reumatoideo, anticuerpos antinucleares, parcial de orina, radiografía de tórax, serología y pruebas de función hepática. ${ }^{4}$ Los resultados negativos de los exámenes paraclínicos ayudan a confirmar el diagnóstico y a descartar otras posibles causas. Teniendo en cuenta la patogénesis de la ulceración, es importante solicitar también recuento de linfocitos y cifras séricas de inmunoglobulina Aque puede estar elevada, asociada con una alteración de los linfocitos T supresores/citotóxicos. 
El tratamiento por lo regular es poco efectivo, en especial en los casos bilaterales. El objetivo principal es evitar la progresión de la enfermedad. Ha demostrado alguna utilidad la aplicación tópica de corticoides, ciclosporina e inhibidores de la colagenasa, además de lente de contacto terapéutico e inmunosupresores sistémicos tipo azatriopina, metrotrexate y ciclofosfamida. ${ }^{1-6} \mathrm{Cuan}-$ do el tratamiento médico falla se debe considerar el quirúrgico como es la resección de $4 \mathrm{~mm}$ de conjuntiva perilimbar ${ }^{5}$ la cual tiene como efecto suspender el influjo de células inflamatorias, inmunoglobulinas, complemento, colagenasas y enzimas proteolíticas provenientes del tejido conjuntival hacia la córnea. Otras opciones quirúrgicas utilizadas en especial cuando se presenta perforación o inminencia de ella son queratoplastia lamelar, colocación de adhesivo tisular (cianoacrilato) y transplante de membrana amniótica, ${ }^{1-6}$ cuando el proceso inflamato- rio se ha resuelto, puede realizarse una restauración quirúrgica de la córnea e intentar rehabilitación de la agudeza visual.

\section{Referencias}

1. Mooren's ulceration. En: Kaufman HE. The cornea. 2nd ed. Boston: Butterworth-Heinemann; 1998. p. 562-66

2. Schanzlin D. Mooren's Ulceration. En: Smolin G. The cornea. 3rd ed. Boston : Little Brown, 1994. p. 408-13

3. Cornea and External Disease: clinical diagnosis and management. En: Krachmer JH, Mannis MJ, Holland EJ. Cornea and cornea color atlas. St. Louis : Mosby, 1997. p. 1359-84

4. Taylor CJ, Smith SI, Morgan CH, et al. HLA and Mooren's ulceration. Br J Ophthalmol. 2000 Jan; 84(1):72-5

5. Watson PG. Management of Mooren's ulceration. Eye (Lond). 1997; 11(Pt 3):349-56

6. Chen J, Xie H, et al. Mooren's ulcer in China : a estudy of clinical characteristics an treatment. Br J Ophthalmol. 2000 Nov; 84(11):1244-9. 